\title{
Formulation and evaluation of fluvastatin sodium drug- in-adhesive transdermal system
}

\author{
Rachel GEEVARGHESE 1, 2 * D, Satish SHIROLKAR ${ }^{1}$ (D) \\ 1 Department of Pharmaceutics, Dr. D.Y. Patil Institute of Pharmaceutical Sciences and Research, Pune, India \\ 2 Department of Pharmaceutics Dr. L. H.Hiranandani College of Pharmacy, Ulhasnagar, Mumbai, India \\ * Corresponding Author. E-mail: rachel_hvl@yahoo.co.in (R.G.); Tel. +91-981-914 0611.
}

Received: 08 October 2019 / Revised: 13 March 2020 / Accepted: 30 March 2020

\begin{abstract}
Current investigation is aimed at designing a fluvastatin sodium loaded drug-in-adhesive patch (DIA Patch ) to overcome the problems associated with the daily oral administration of the drug. The patches were prepared by solvent casting method using acrylate emulsion polymers like covinax 525-78, mowinyl 461 and novacryl PSR32 which served as sustained release matrix polymer and adhesive. Methocel K-15M was added as a solubilizer whereas transcutol, oleic acid and isopropyl myristate were tried as permeation enhancers for the drug-in-adhesive patch. The combination of mowinyl-isopropyl myristate patch was further optimized by 32 factorial design to study the effect of two independent variables i.e. concentration of solubilizer and permeation enhancer on responses i.e.\% drug release, tensile strength and peel adhesion strength. The formulation was further evaluated for its lipid lowering activity and skin irritation index. The \% cumulative release of drug at the end of $24 \mathrm{~h}$ was found to be $87.74 \%$. The formulation shows tensile strength of $12.75 \mathrm{~kg} / \mathrm{cm}^{2}$ and peel adhesion strength of $32.44 \mathrm{~N} / 25 \mathrm{~mm}$. The Primary irritation index (PII) for DIA patch was found to be 0.22 . The fluvastatin sodium loaded DIA patch significantly inhibits serum cholesterol and triglyceride levels as compared to oral control $(\mathrm{p}<0.01)$ in triton WR 1339 induced hyperlipidemic rat. Hence the developed transdermal patch could be acceptable for transdermal use.
\end{abstract}

KEYWORDS: Pressure-sensitive-adhesive; fluvastatin sodium; drug-in-adhesive patch; \% cumulative release; peel adhesion strength; total cholesterol.

\section{INTRODUCTION}

Preparation of transdermal patches consists of three basic designs [1,2] reservoir patch or RP, matrix or monolithic patch (MP), and drug-in-adhesive patch or DIAP. DIAP and MP score over RP in terms of patient compliance, manufacturing process control, quality control and continuous product improvement. Statins are generally recognized as the treatment of choice in patients with hypercholesterolemia. Fluvastatin sodium [3] is one of the most potent statins and is approved for reducing circulating low-density lipoprotein cholesterol (LDL-C) levels. It is rapidly and almost completely absorbed (>90\%), but undergoes extensive first pass metabolism. Oral bioavailability is $24 \%$ when a one $\mathrm{mg}$ dose is given. Thus, increased doses of the drug is usually used to obtain the expected therapeutic efficacy. The immediate-release formulations are reported to show nonlinear pharmacokinetics at doses greater than $20 \mathrm{mg}$. This may lead to increased risk of adverse effects, like dose-related musculoskeletal and hepatic toxicities. Transdermal drug delivery system is advantageous over other routes of administration in evading the first-pass metabolism by the liver, exempt from the impacts of the gastrointestinal fluids, provides controllable sustained effects, reduces toxicity and side-effects leading to better therapeutic effect. Thus fluvastatin sodium with a molecular weight of 411.46 and a short half-life of $3 \mathrm{~h}$ is an ideal candidate for transdermal drug delivery.

Three water based acrylate pressure sensitive adhesives (PSA) were selected for the present study. These emulsion polymers were selected on the basis of $\mathrm{pH}$, glass transition temperature $\left(\mathrm{T}_{\mathrm{g}}\right)$ and solid content [4]. Acrylate polymers used as PSA typically will have a $\mathrm{T}_{\mathrm{g}}$ of $-20^{\circ} \mathrm{C}$, preferably from -40 to $-80^{\circ} \mathrm{C}$. This low $\mathrm{T}_{\mathrm{g}}$ gives the PSA its soft, tacky properties. The above three acrylate polymers were tried for their film forming properties using solvent evaporation technique [5-10]. These polymers when used alone remained extremely tacky and the films formed were difficult to remove from the mold after drying at room temperature. The formulated drug loaded patches were subjected to a preliminary in vitro diffusion study where it was seen that all three polymers released $30-40 \%$ of drug within 1-3 hours and maximum amount of drug released at

How to cite this article: Geevarghese R, Shirolkar S. Formulation and evaluation of fluvastatin sodium drug-in-adhesive transdermal system. J Res Pharm. 2020; 24(4): 562-571. 
the end of 24 hours was in the range of 45-48\%. Crystallization of drug is reported in case of drug-in-adhesive patches. Several additives like hydoxy propyl methyl cellulose (HPMC), polyvinyl pyrrolidine (PVP) etc. are known to inhibit crystallization by preventing crystal nucleation, adsorption onto crystals or forming additive drug co-precipitates. All these mechanisms can increase permeation and improve release profile of drugs $[11,12]$. Thus it was thought to replace a part of the acrylate emulsion polymer with methocel K15M.

The treatment of hyperlipidemia is often long lasting. In this case it is very important that a steady concentration of drug be maintained in the plasma and the dosage regimen be as simple as possible for the patient. From the literature review on hyperlipidemia, the available therapies and the challenges associated with the current therapies emerged the research problem to be addressed. Hence it was thought worthwhile to formulate a once a day drug-in-adhesive patch for transdermal delivery of fluvastatin sodium as an alternative to oral therapy for the treatment of hyperlipidemia.

\section{RESULTS AND DISCUSSION}

\subsection{Evaluation of preliminary batches}

The $\%$ cumulative release at the end of $24 \mathrm{~h}$ for the formulations was found to be between $42 \%$ to $86 \%$. The formulated patches showed thickness ranging from $0.11 \mathrm{~mm}$ to $0.18 \mathrm{~mm}$. The $\%$ drug content for all patches was in the range of $95.27 \%$ to $97.67 \%$. The patches showed moisture content and moisture uptake in the range of $4.30 \%$ to $5.78 \%$ and $6.18 \%$ to $7.08 \%$ respectively. Folding endurance values of the patches were greater than 250 folds. Evaluation of the preliminary batches show that the patches have tensile strength values in the range of 4.52 to $11 \mathrm{~kg} / \mathrm{cm}^{2}$ and peel adhesion strength in the range of 19.9 to $26.67 \mathrm{~N} / 25 \mathrm{~mm}$.

\subsection{Factorial design based formulation}

Based on evaluation of preliminary batches of formulation, mowinyl-isopropyl myristate (MIPM) patch with\%cumulative release of $86.4 \%$ at the end of $24 \mathrm{~h}$, tensile strength value of $4.72 \mathrm{~kg} / \mathrm{cm}^{2}$ and peel adhesion strength of $26.65 \mathrm{~N} / 25 \mathrm{~mm}$ was selected for further study. This combination was subjected to a $3^{2}$ factorial design. The experiments were performed as shown in Table 1.

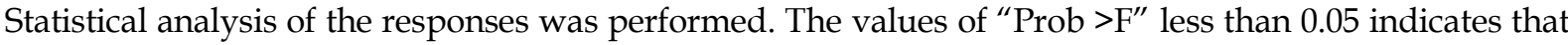
the model terms are significant. Regression analysis was performed on the results and a polynomial equation was derived for the responses as a function of the independent variables. The polynomial equation can be used to draw conclusions after considering the magnitude of each coefficient and the mathematical sign it carries. Polynomial equation (Equation 1, 2 and 3) in terms of coded factors:

$\%$ cumulative release $=81.09+7.52 * A+2.49 * B-1.23 * A B$

[Eq. 1]

Peel Adhesion Strength $=+33.80-6.27^{*} \mathrm{~A}-6.34^{*} \mathrm{~B}$

[Eq. 2]

Tensile Strength $=+12.53-2.79 * \mathrm{~A}-2.70 * \mathrm{~B}-1.0$

[Eq. 3]

Table 1. $3^{2}$ Experimental design for mowinyl-isopropyl myristate (MIPM) transdermal patch.

\begin{tabular}{|c|c|c|c|c|}
\hline Formulation code & $X_{1} X_{2}$ & $\begin{array}{c}\% \text { Cumulative } \\
\text { Release }\end{array}$ & $\begin{array}{c}\text { Peel adhesion } \\
\text { strength } \\
(\mathrm{N} / 25 \mathrm{~mm})\end{array}$ & $\begin{array}{c}\text { Tensile } \\
\text { Strength } \\
\left(\mathrm{Kg} / \mathrm{cm}^{2}\right)\end{array}$ \\
\hline $\mathrm{MIPM}_{1}$ & $-1+1$ & 77.94 & 32.47 & 13.45 \\
\hline $\mathrm{MIPM}_{2}$ & $-1-1$ & 70.13 & 46.85 & 17.09 \\
\hline $\mathrm{MIPM}_{3}$ & $\begin{array}{ll}0 & 0\end{array}$ & 80.36 & 32.91 & 12.81 \\
\hline $\mathrm{MIPM}_{4}$ & $0+1$ & 82.58 & 28.22 & 9.37 \\
\hline $\mathrm{MIPM}_{5}$ & $+1 \quad 0$ & 88.43 & 26.47 & 9.89 \\
\hline $\mathrm{MIPM}_{6}$ & $\begin{array}{ll}0 & -1\end{array}$ & 78.34 & 40.00 & 14.25 \\
\hline $\mathrm{MIPM}_{7}$ & $+1-1$ & 87.74 & 34.06 & 13.81 \\
\hline $\mathrm{MIPM}_{8}$ & $\begin{array}{ll}-1 & 0\end{array}$ & 73.62 & 41.00 & 16.00 \\
\hline $\mathrm{MIPM}_{9}$ & $+1+1$ & 90.63 & 22.20 & 6.10 \\
\hline
\end{tabular}




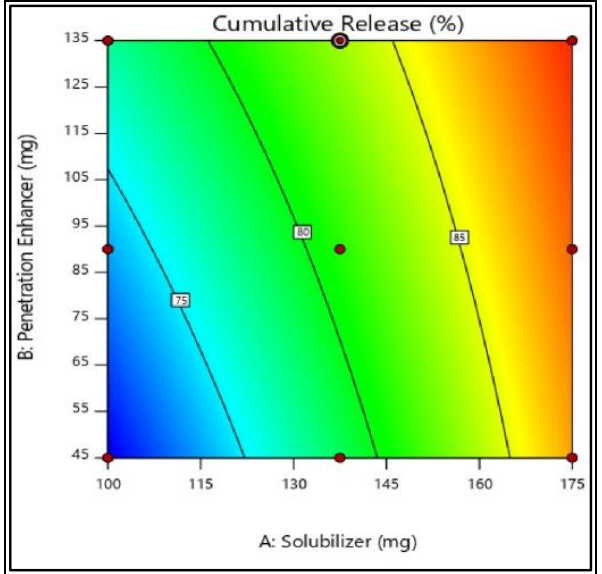

A

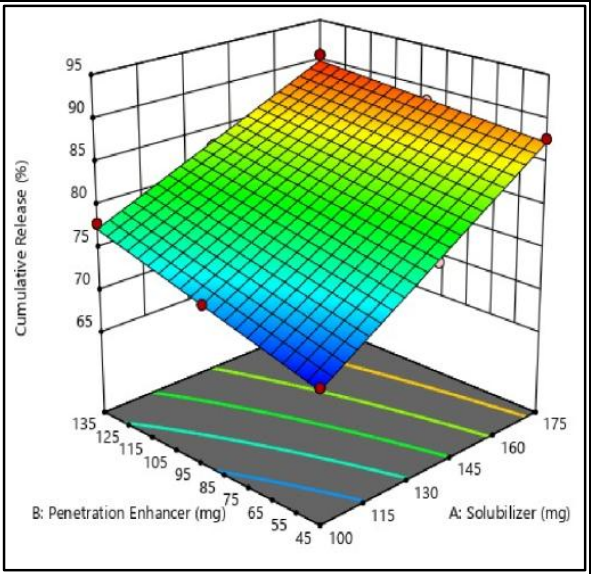

B

Figure 1. Percent cumulative release from MIPM patch A: contour plot plot B: 3D response surface.

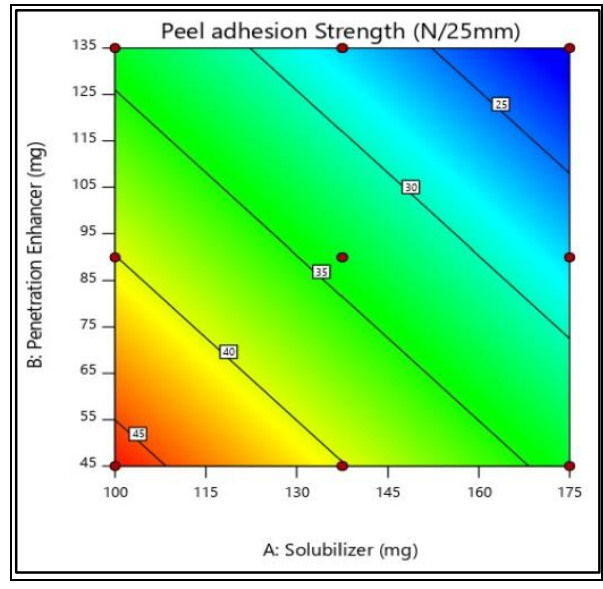

A

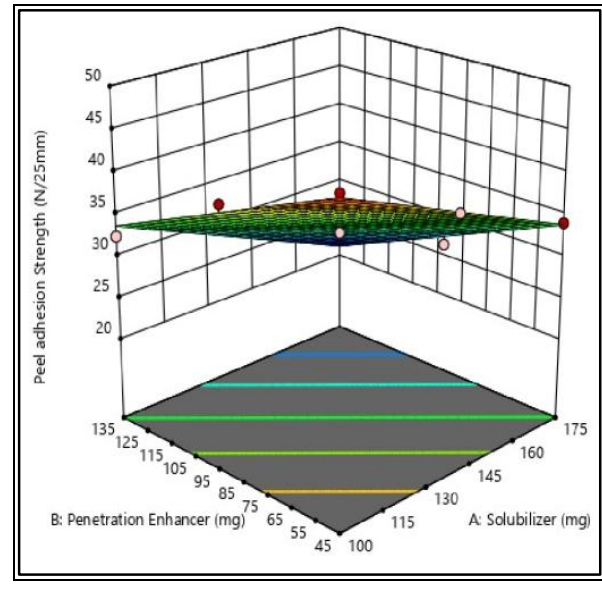

B

Figure 2: Peel adhesion strength of MIPM patch A: contour plot B: 3D response surface plot.

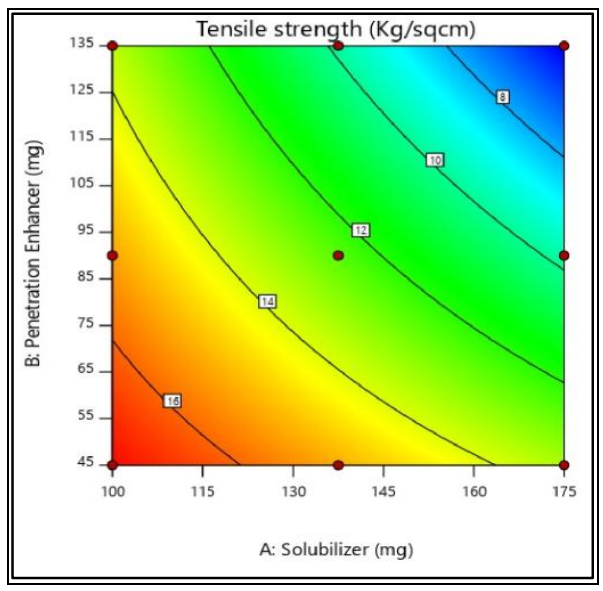

A

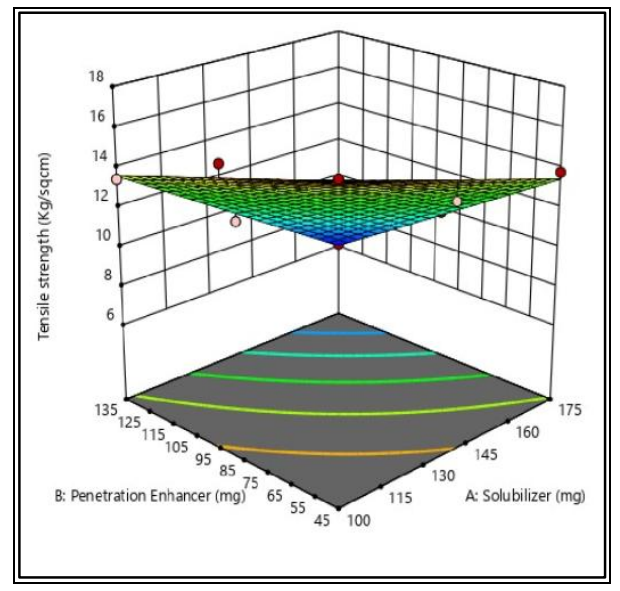

B

Figure 3: Tensile strength of MIPM patch A: contour plot B: 3D response surface plot.

From Figures 1, 2 and 3 the following observations can be made. It can be seen that high levels of solubilizer and permeation enhancer increases the \% cumulative release. Formulation MIPM9 gave highest percentage of drug release $(90.63 \%)$ as compared to the formulation $\mathrm{MIPM}_{2}(70.13 \%)$. As the concentration of hydrophilic polymer methocel $\mathrm{K} 15 \mathrm{M}$ increased in the formulations, the drug release rate increased substantially 
[13-15]. It may be due to initial rapid dissolution of the hydrophilic polymer when the patch is in contact with the hydrated dialysis membrane resulting in the accumulation of high amounts of drug on the surface and thus leading to saturation with drug molecules. The above result can also be attributed to lipophilicity of the isopropyl myrisitate (IPM). IPM is a lipophilic solvent having a high $\log P$ value of 7.17. Parhi $R$ etal., 2018 reported role of IPM in partitioning of the drug from simvastatin loaded transdermal patch to lipophilic membrane and subsequently to the acceptor phase [7]. The lower values of $T_{g}$ due to the plasticization effect of IPM leading to less rigid and more relaxed network of the pressure sensitive adhesive (PSA) polymer was reported by Zhao C etal., 2016 [16]. Increased flexibility of the PSA polymer by increasing the intermolecular separation of the polymer chains may be the reason for higher release of drug from the patches.

However increase in levels of penetration enhancer shows a decrease in the values of tensile strength and peel adhesion. A negative sign of coefficient for penetration enhancer indicates an antagonistic effect of this variable on tensile strength and peel adhesion strength. So at a low level of this variable higher value of tensile strength and peel adhesion strength is seen. This may be due to IPM-induced plasticization [16] of the PSA leading to a depression of the glass transition temperature and loss of the soft, tacky properties that are necessary in a PSA.

Numerical optimization data provided by the software gives solutions for optimized batches of formulation. As can be seen from Table 2, MIPM patch prepared using $175 \mathrm{mg}$ of solubilizer and $45 \mathrm{mg}$ of penetration enhancer gave response values which are in close agreement with the predicted values provided by the software.

Table 2. Observed and predicted values for optimized patch.

\begin{tabular}{lccccc}
\hline Optimized Patch & $\begin{array}{c}\text { A:Solubilizer } \\
\mathbf{m g}\end{array}$ & $\begin{array}{c}\text { B:Penetration } \\
\text { Enhancer } \\
\mathbf{m g}\end{array}$ & $\begin{array}{c}\text { Cumulative } \\
\text { Release } \\
\mathbf{\%}\end{array}$ & $\begin{array}{c}\text { Peel adhesion } \\
\text { Strength } \\
\mathbf{N} / \mathbf{2 5} \mathbf{m m}\end{array}$ & $\begin{array}{c}\text { Tensile } \\
\text { strength } \\
\mathbf{K g} / \mathbf{c m}^{2}\end{array}$ \\
\hline Observed Value & 175 & 45 & 88.68 & 32.44 & 12.75 \\
Predicted Value & 175 & 45 & 87.81 & 33.45 & 13.46 \\
\hline
\end{tabular}

\subsection{Primary skin irritation study}

No sensitization was noted among rabbits that were treated with transdermal patch or the placebo patch as shown in Table 3. Erythema and edema were not observed after the challenge in this experiment. Average primary skin irritation index was found to be 0.11 for placebo patch and 0.22 for DIA patch. According to Draize et al. compounds producing scores of two or less are considered non-irritant. Hence, the transdermal patches were free of skin irritation.

Table 3. Results of primary skin irritation study.

\begin{tabular}{|c|c|c|c|c|c|c|}
\hline \multicolumn{7}{|c|}{ Placebo transdermal patch $(n=3)$} \\
\hline \multirow{2}{*}{$\begin{array}{l}\text { Skin reaction } \\
\text { Observation time }(\mathrm{h})\end{array}$} & \multicolumn{3}{|c|}{ Erythema } & \multicolumn{3}{|c|}{ Edema } \\
\hline & 24 & 48 & 72 & 24 & 48 & 72 \\
\hline Total Score & 0 & 0 & 0 & 1 & 0 & 0 \\
\hline Mean Score & 0 & 0 & 0 & 0.33 & 0 & 0 \\
\hline Total of mean score & \multicolumn{6}{|c|}{0.33} \\
\hline PII & \multicolumn{6}{|c|}{0.11} \\
\hline \multicolumn{7}{|c|}{ Fluvastatin sodium loaded DIA patch $(n=3)$} \\
\hline Skin reaction & \multicolumn{3}{|c|}{ Erythema } & \multicolumn{3}{|c|}{ Edema } \\
\hline Observation time (h) & 24 & 48 & 72 & 24 & 48 & 72 \\
\hline Total Score & 0 & 1 & 0 & 0 & 1 & 0 \\
\hline Mean Score & 0 & 0.33 & 0 & 0 & 0.33 & 0 \\
\hline Total of mean score & & & & 66 & & \\
\hline PII & & & & 22 & & \\
\hline
\end{tabular}

\subsection{In vivo study}

Schurr et al., 1972 [17] demonstrated that parenteral administration of a dose of tritonWR-1339 to adult rats induced hyperlipidemia. As per the report published by Otway and Robinson, 1967 [18] the large increase 
in cholesterol and triglyceride due to triton WR-1339 injection results mostly from an increase of VLDL secretion by the liver accompanied by a strong reduction of VLDL and LDL catabolism. Treatment with triton (disease control) resulted in significant $(\mathrm{p}<0.01)$ increase in cholesterol levels as compared to normal control group indicating induction of hyperlipidemia. Figures 4 and 5 represent cholesterol and triglyceride levels respectively at $0 \mathrm{~h}$ (initial reading) and $24 \mathrm{~h}$ for treated groups of animals $(\mathrm{n}=6)$. Data are represented as mean \pm SEM (Standard error of mean). The group means were compared for significant difference using Bonferroni multiple comparison test. Formulation control (transdermal film) significantly $(p<0.01)$ inhibited cholesterol levels as compared to oral control $(\mathrm{p}<0.01)$. Treatment with triton (disease control) resulted in significant $(p<0.01)$ increase in triglyceride levels as compared to normal control group indicating induction of hyperlipidemia. Formulation control (transdermal film) significantly $(\mathrm{p}<0.01)$ inhibited triglyceride levels as compared to oral control $(\mathrm{p}<0.01)$.

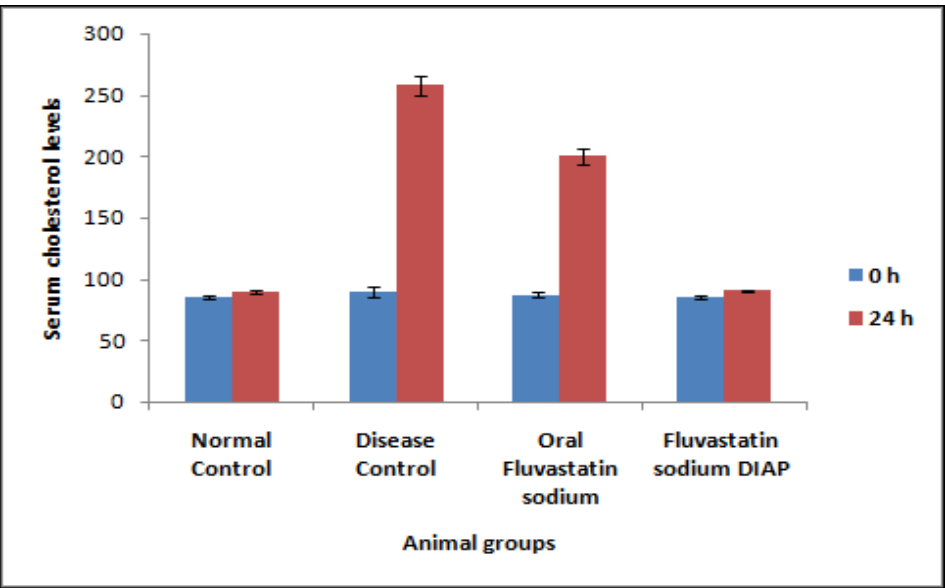

Figure 4. Serum levels of cholesterol following oral and transdermal administration of fluvastatin sodium.

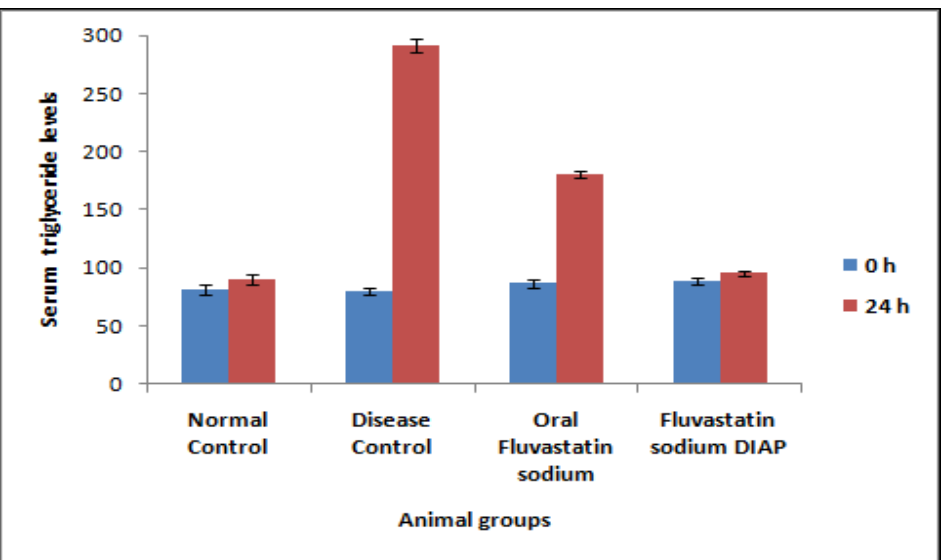

Figure 5. Serum levels of triglyceride following oral and transdermal administration of fluvastatin sodium.

\subsection{Solid state characterization of DIA patch}

\subsubsection{Differential scanning calorimetry}

The DSC analysis of fluvastatin sodium shows a sharp endothermic peak at $152^{\circ} \mathrm{C}$ corresponding to its melting point as shown in Figure 6A. The sharp endothermic peak at $152^{\circ} \mathrm{C}$ disappeared in case of DIA patch i.e. Figure $6 \mathrm{~B}$ which may be due to the dispersion of drug in molecular form in the adhesive and can also be attributed to the small amount of drug present in the formulation. Such behaviour is reported by Li J et al., 2018 in case of fluvastatin $-\beta$ cyclodextrin nanosuspensions [19], Sharma P et al., 2017 for drug in matrix type of transdermal patch [20 ].

\subsubsection{X-ray diffraction studies}


Figure 7A shows characteristic intense peaks between $2 \theta$ of 6 and 25, however in case of DIA patch the intensity of peaks were decreased indicating amorphous nature of drug [19] as seen in Figure 7B.

\subsubsection{Scanning electron microscopy}

Transdermal matrix systems are known to be thermodynamically unstable due to crystallization of drug after formulation and an increasing tendency of system to crystallize further during storage. Antinucleant polymers like the celluloses, e.g. hydroxypropylmethyl cellulose or the pyrrolidone, e.g. polyvinylpyrrolidone have been studied extensively [13]. As can be seen in Figure 8, SEM micrograph of patch does not show any evidence of crystallization of drug indicating the presence of drug in the molecular form throughout the adhesive matrix. Absence of crystal formation may be due to drug loading below saturation levels or it may be due to presence of methocel K15 M that prevents collision between drug molecules and hence nuclei formation [20].

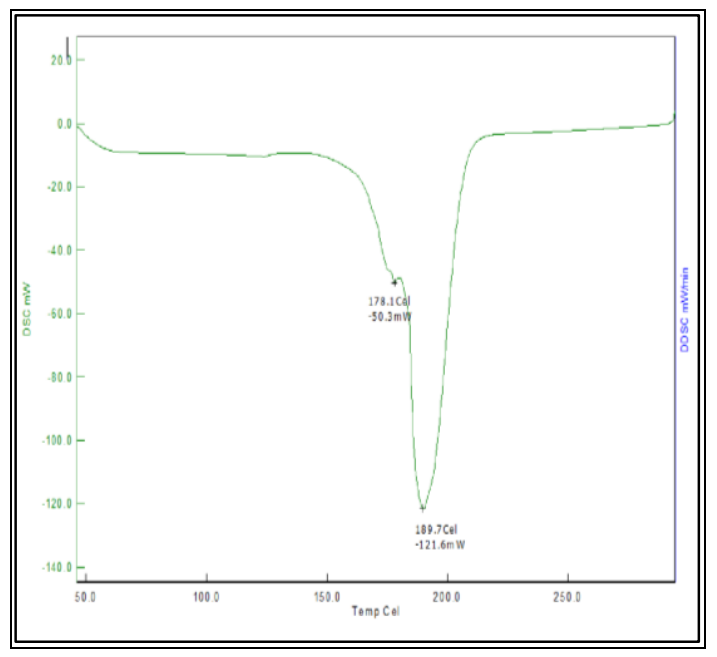

A

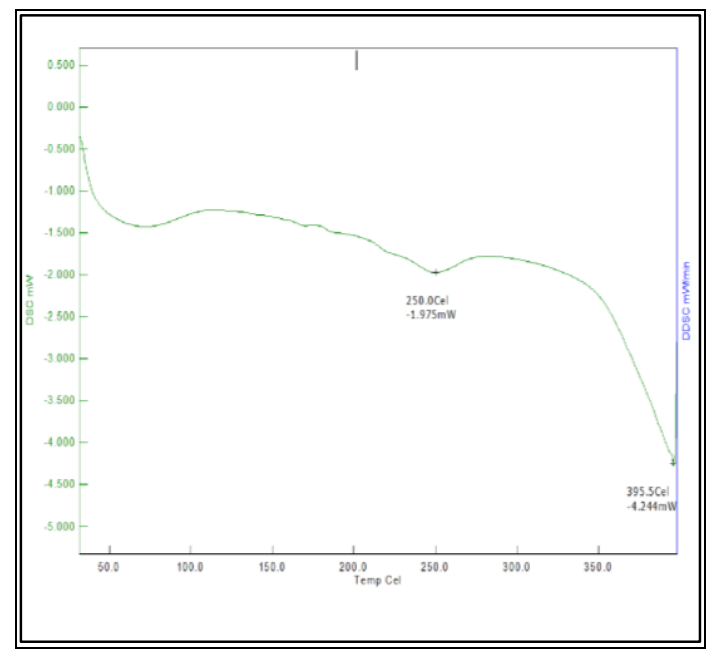

B

Figure 6. DSC Thermogram of A: fluvastatin sodium B: fluvastatin sodium DIA patch.

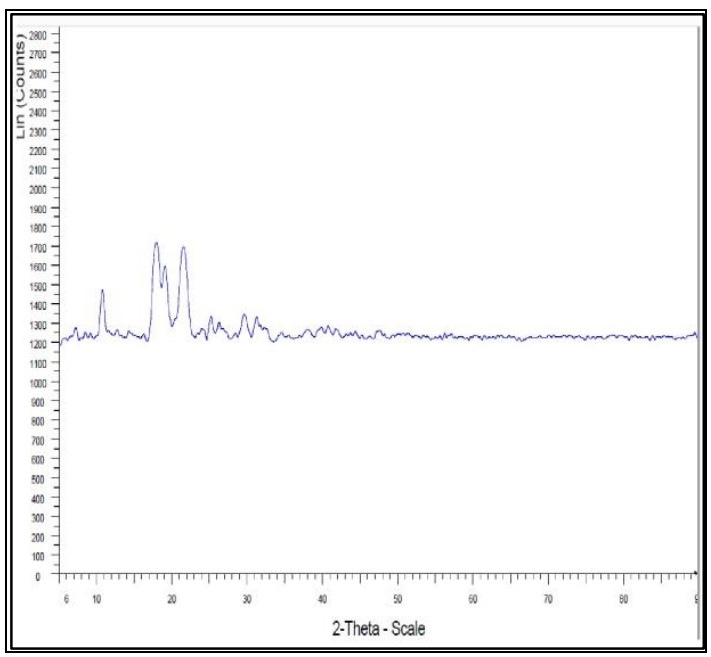

A

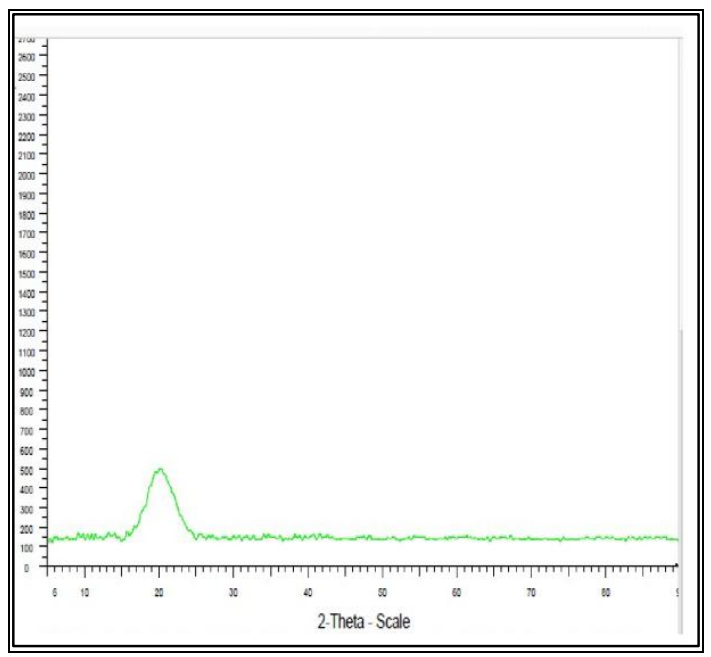

B

Figure 7. X-Ray diffraction pattern for A: fluvastatin sodium B: and fluvastatin sodium DIA patch.

\section{CONCLUSION}

Thus the present study involves formulation of a transdermal patch of fluvastatin sodium using a waterbased pressure sensitive hydrophobic adhesive matrix. Pressure sensitive adhesives used in this study are waterbased adhesives wherein the hydrophobic pressure sensitive adhesive polymer is dispersed in water with the help of surfactants. Such water-based adhesives provide inherent advantages of safety and reduced 
environmental problems over solvent-based pressure sensitive adhesives. It can be stated that acrylic emulsion PSA i.e. mowinyl can provide sustained delivery of the drug as well as impart adhesive properties to the DIA patch. The incorporation of methocel K15M and IPM into the drug-in-adhesive transdermal patch modified drug release, peel adhesion strength and tensile strength of the patch. This phenomenon is attributed to the plasticization effect of IPM on the PSA. The results indicate the need to maintain a fine balance between drug release enhancement and adhesive properties of the transdermal patch. From the pharmacodynamic studies, it can be concluded that fluvastatin sodium loaded drug-in-adhesive patch showed superior lipid lowering as compared to the fluvastatin sodium oral formulation probably due to increased solubility and enhanced permeation of the drug by a combination of solubilizer and permeation enhancer used in formulating the DIA patch. The transdermal formulation can be considered as a potential alternative to oral dosage form.

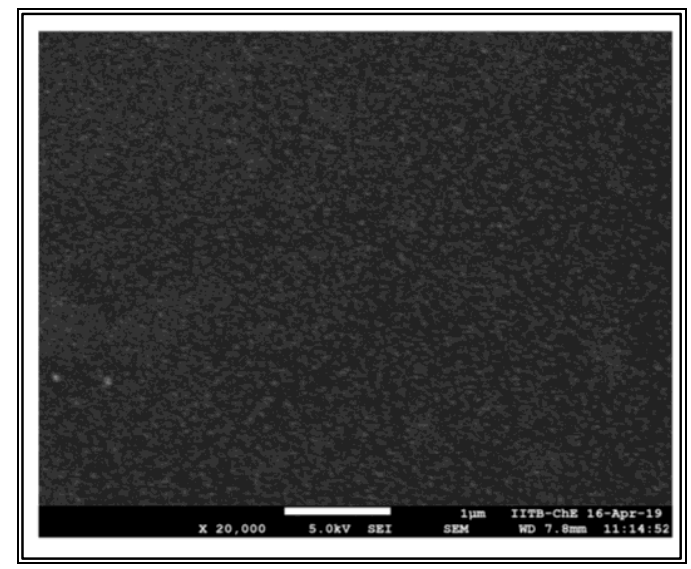

Figure 8. SEM image of optimized formulation of fluvastatin sodium DIA patch.

\section{MATERIALS AND METHOD}

\subsection{Materials}

Fluvastatin sodium was received as gift sample from Sun Pharma Ltd. Mumbai. Acrylate polymers mowinyl 461 (Nippon Synthetic Chemical Industry Ltd), novacryl PSR 32 (Omnova Solution Inc) and covinax 525-78 (Franklin Adhesives and Polymers) were received as gift samples. Transcutol CG USP/NF was received as gift sample from Gattefosse SAS. Other chemicals and solvents used in the study were of analytical grade.

\subsection{Preparation of transdermal patch}

Water based acrylate pressure sensitive adhesives were selected for the present study [21,22]. These emulsion polymers were selected on the basis of $\mathrm{pH}$, glass transition temperature $\left(\mathrm{T}_{\mathrm{g}}\right)$, solid content etc. DIA patches were made from three different acrylate [23] emulsion polymers covinax, mowinyl and novacryl using different permeation enhancers like transcutol, oleic acid and isopropyl myristate as shown in Table 4. Weighed quantities of drug, acrylate polymer, solubilizer and permeation enhancer were taken, water was added to make up the required weight and the mixture stirred on a magnetic stirrer for one hour. The patches were prepared by solvent evaporation method using rectangular glass moulds of size $6.7 \times 4.5 \mathrm{~cm}$. All the patches were wrapped in aluminium foil and stored in desiccators till further evaluation.

Table 4. Composition of preliminary batches of DIA patch.

\begin{tabular}{lccccccccc}
\hline \multirow{2}{*}{ Content } & \multicolumn{10}{c}{ Formulation Code } \\
\cline { 2 - 11 } & $\mathbf{P}_{\mathbf{1}}$ & $\mathbf{P}_{\mathbf{2}}$ & $\mathbf{P}_{\mathbf{3}}$ & $\mathbf{P}_{\mathbf{4}}$ & $\mathbf{P}_{5}$ & $\mathbf{P}_{\mathbf{6}}$ & $\mathbf{P}_{\mathbf{7}}$ & $\mathbf{P}_{\mathbf{8}}$ & $\mathbf{P}_{\mathbf{9}}$ \\
\hline Fluvastatin & 0.01 & 0.01 & 0.01 & 0.01 & 0.01 & 0.01 & 0.01 & 0.01 & 0.01 \\
Covinax & 0.8 & - & - & 0.8 & - & - & 0.8 & - & - \\
Mowinyl & - & 0.8 & - & - & 0.8 & - & - & 0.8 & \\
Novacryl & - & - & 0.8 & - & - & 0.8 & - & - & 0.8 \\
Transcutol & 0.18 & 0.18 & 0.18 & & & & - & - & - \\
Oleic acid & - & - & - & 0.05 & 0.05 & 0.05 & & & \\
Isopropyl myrisitate & - & - & - & - & - & - & 0.09 & 0.09 & 0.09 \\
\hline
\end{tabular}




\begin{tabular}{lccccccccc}
\hline Methocel K15M & 0.1 & 0.1 & 0.1 & 0.1 & 0.1 & 0.1 & 0.1 & 0.1 & 0.1 \\
Distilled water .q.s & 10 & 10 & 10 & 10 & 10 & 10 & 10 & 10 & 10 \\
\hline
\end{tabular}

*All weights are in gram

\subsection{Evaluation of preliminary batches}

The formulated transdermal patches were evaluated for various physiochemical properties like thickness, drug content uniformity, percentage moisture content, percentage moisture uptake, folding endurance, tensile strength, peel adhesion and in vitro drug release as reported in literature [24-25].

\subsection{Factorial design based formulation}

On the basis of initial screening studies drug-in-adhesive patch containing acrylate polymer mowinyl and permeation enhancer isopropyl myrisitate (IPM) was subjected to $3^{2}$ experimental design (Design-Expert ${ }^{\circledR}$ Software Stat-Ease, Inc) wherein two factors i.e. Solubilizer (methocel K-15M) and permeation enhancer (IPM) was varied at three levels and the response measured was in vitro drug release, peel adhesion strength and tensile strength [26]. Analysis of variance (ANOVA) and all statistical analysis were also performed using the same software. The coded values for the design layout is as shown in Table 5.

Table 5. Experimental domain for mowinyl-isopropyl myristate (MIPM) transdermal patch.

\begin{tabular}{lcccc}
\hline Factor & $\begin{array}{c}\text { Independent } \\
\text { variable }\end{array}$ & $\begin{array}{c}\text { Lower level } \\
\text { (Coded-1) }\end{array}$ & $\begin{array}{c}\text { Middle } \\
\text { Level } \\
\text { (Coded 0) }\end{array}$ & $\begin{array}{c}\text { Upper } \\
\text { level(Coded+1) }\end{array}$ \\
\hline $\begin{array}{l}\text { Methocel K-15M } \\
(\mathrm{mg})\end{array}$ & $\mathrm{X}_{1}$ & 100 & 137.5 & 175 \\
$\begin{array}{l}\text { Isopropyl myristate } \\
(\mathrm{mg})\end{array}$ & $\mathrm{X}_{2}$ & 45 & 90 & 135 \\
\hline
\end{tabular}

\subsection{Primary skin irritation study}

The animal protocol to carry out in vivo study was reviewed and approved by institutional animal ethics committee (Protocol approval No: PCEU 02/IAEC/2016 dated 18-11-16). Albino rabbits weighing 1.5 to 2.0 $\mathrm{kg}$ and 24 months of age was used in this study $(n=03)$. They were housed in cages in the animal house under controlled temperature $\left(27 \pm 2^{\circ} \mathrm{C}\right)$ and light conditions, fed a standard laboratory diet and water provided ad libitum. Hair from the dorsal surface was removed by shaving $24 \mathrm{~h}$ before the test. The animals were examined at grading intervals of 24,48 and $72 \mathrm{~h}$ for the presence of erythema and edema according to Draize dermal irritation scoring system [27]. For each animal, the dermal response scores (sum of the scores for erythema formation and edema formation) at 24, 48 and $72 \mathrm{~h}$ after the removal of the patches were summed up and then divided by 3 to obtain a mean irritation score per time point. The mean scores at 24,48 and $72 \mathrm{~h}$ were summed and the average derived to obtain the PII.

\subsection{In vivo study}

\subsubsection{Standardization model for triton induced hyperlipidemia}

Hyperlipidemia was induced in four rats by injecting intraperitoneally $250 \mathrm{mg} / \mathrm{kg}$ body weight of triton WR 1339 dissolved in saline solution whereas four rats were treated with normal saline solution (control). The levels of cholesterol and triglyceride were measured for each using standard bioanalytical kits (Randox) to standardize the dose of inducing agent.

\subsubsection{Lipid lowering activity of fluvastatin sodium loaded transdermal patch}

Male Wistar rats, 200-260 gm weight, were selected for in vivo studies. All animals were fed with standard pelleted diet and water and were housed in the experimental room having temperature $25 \pm 2{ }^{\circ} \mathrm{C}$, controlled humidity conditions and $12 \mathrm{~h}$ light-dark cycle. They were acclimatized for 2 weeks before the start of the experiment. Institutional animal ethics committee approved all animal procedures (Protocol approval No: PCEU 02/IAEC/2016 dated 18-11-16). Rats were fasted overnight before experiment. The hair on dorsal surface of the rats were removed by shaving prior to the day of experiment. Animals were divided into 4 
groups ( $\mathrm{n}=6)$. Group 1 was treated as normal control. Hyperlipidemia was induced in Groups 2 to 4 . Group 2 was treated as disease control, Group 3 was treated with oral suspension of fluvastatin sodium whereas Group 4 was treated with fluvastatin sodium loaded transdermal patch respectively [28-30].

\subsection{Solid state characterization of DIA patch}

\subsubsection{Differential scanning calorimetry}

DSC was carried out to determine the physical state in which fluvastatin sodium exists in DIA patch DSC analysis was performed using a (DSC 6220 SII Nanotechnology, SEIKO) differential scanning calorimeter. Accurately weighed samples were placed in aluminium pans sealed with a lid. $\mathrm{Al}_{2} \mathrm{O}_{3}$ was used as the reference. During the scanning process, a heating rate of $10^{\circ} \mathrm{C} /$ minute was applied in the temperature range from $20^{\circ} \mathrm{C}$ to $150^{\circ} \mathrm{C}$.

\subsubsection{X-ray diffraction studies}

XRD studies were performed using the Bruker D 8 Advance Instrument. The samples were scanned over a $2 \theta$ range of $0^{\circ}-90^{\circ}$ at a rate of $0.05^{\circ}$ / second.

\subsubsection{Scanning electron microscopy}

Scanning electron Microscopy was used for the study. It produces images of sample by scanning the surface with a focused beam of electrons. The electrons interact with atoms in the sample, producing various signals that contain information about the surface topography. JSM 7600F Microscope (JEOL, Tokyo, Japan) was used for studying the morphology of DIA patch. Patch was subjected to analysis, image was collected at an acceleration voltage of $5.0 \mathrm{KV}$ using back scattered electron detector.

Author contributions: Concept -R.G., S.S.; Design -R.G., S.S.; Supervision - R.G., S.S.; Materials - R.G.; Data Collection and/or Processing - R.G., S.S.; Analysis and/or Interpretation - R.G., S.S.; Literature Search - R.G., S.S.; Writing - R.G., S.S.; Critical Reviews - R.G., S.S.

Conflict of interest statement: The authors declare no conflict of interest.

\section{REFERENCES}

[1] Pastore M , Kalia Y, Horstmann M, Roberts M. Transdermal patches : history, development and pharmacology. Br J Pharmacol. 2015; 172(9): 2179-2209. [CrossRef]

[2] Al Hanbali O, Khan H, Sarfra M, Arafat M, Ijaz S, Hameed A.Transdermal patches: design and current approaches to painless drug delivery. Acta Pharma. 2019; 69(2): 197-215. [CrossRef]

[3] Schechter M. Chemical, pharmacokinetic and pharmacodynamic properties of statins: an update. Fundam Clin Pharmacol. 2005; 19: 117-125. [CrossRef]

[4] Puri A, Bhattaccharjee S, Zhang W, Clark M, Singh O, Doncel G, Banga A. Development of a transdermal delivery system for tenofovir alafenamide, a prodrug of tenofovir with potent antiviral activity against HIV and HBV. Pharmaceutics. 2019; 11(173): 1-29. [CrossRef]

[5] Regenthal R, Voskanian M, Baumann F, Teichert J, Brätter C, Aigner A, Abraham G. Pharmacokinetic evaluation of a transdermal anastrozole-in-adhesive formulation. Drug Des Devel Ther. 2018; 12: 3653-3664. [CrossRef]

[6] Siafaka P, Barmpalexis P,Lazaridou M ,Papageorgiou G, Koutris E, Karavas E, Kostoglou M, Bikiaris D.Controlled release formulations of risperidone antipsychotic drug in novel aliphatic polyester carriers:data analysis and modelling. Eur J Pharm Biopharm. 2015; 94: 473-484. [CrossRef]

[7] Parhi R, Padilam S .In vitro permeation and stability studies on developed drug-in-adhesive transdermal patch of simvastatin. Bulletin of Faculty of Pharmacy, Cairo University. 2018; 56(1): 26-33. [CrossRef]

[8] Okur N, Filippousi A, Okur M, Ayla S, Caglar E, Yoltas A, Siafaka P. A novel approach for skin infections: controlled release topical mats of poly(lactic acid)/polyethylene succinate blend containiny voriconazole. J Drug Deliv Sci Technol. 2018; 46: 74-86. [CrossRef]

[9] Okur N, Hökenek N, Okur M, Ayla S, Yoltaş A, Siafaka P, Cevher E. An alternative approach to wound healing field; new composite films from natural polymers for mupirocin dermal delivery. Saudi Pharm J. 2019; 27(5): 738-752. [CrossRef] 
[10] Jafri I, Shoaib M, Yousuf R, Ali F. Effect of permeation enhancers on in vitro release and transdermal delivery of lamotrigine from Eudragit ${ }^{\circledR}$ RS100 polymer matrix-type drug in adhesive patches. Prog Biomater. 2019; 8(2): 91-100. [CrossRef]

[11] Hsieh L, Box K, Taylor S. Assessing the Impact of polymers on the $\mathrm{pH}$-induced precipitation behaviour of poorly water soluble compounds using synchrotron wide angle X-ray scattering. J Pharm Sci. 2014; 103: $2724-2735$. [CrossRef]

[12] Suys J, Chalmers D, Pouton C, Porte C.Polymeric precipitation inhibitors promote fenofibrate supersaturation and enhance drug absorption from a type IV lipid based formulation. Mol Pharm. 2018; 15(6): 2355-2371. [CrossRef]

[13] Hadgraft H, Lane M . Drug crystallization - implications for topical and transdermal delivery. Expert Opin Drug Deliv. 2016; 13(6): 817-830. [CrossRef]

[14] Weng W, Quan P, Liu C, Zhao H, Fang L. Design of a drug-in-adhesive transdermal patch for risperidone: effect of drug-additive interactions on the crystallization inhibition and in vitro/in vivo correlation study. J Pharm Sci. 2016; 105(10): 3153-3161. [CrossRef]

[15] Jain P, Banga AK .Inhibition of crystallization in drug-in-adhesive-type transdermal patches. Int J Pharm. 2010 ; 394 (1-2): 68-74. [CrossRef]

[16] Zhao C, Quan P, Liu C, Li Q, Fang L.Effect of isopropyl myristate on the viscoelasticity and drug release of a drugin-adhesive transdermal patch containing blonanserin. Acta Pharm Sin B. 2016; 6(6): 623-628. [CrossRef]

[17] Schurr P , Schultz J , Parkinson T . Triton-induced hyperlipidemia in rats as an animal model for screening hypolipidemic drugs. Lipids. 1972; 7(1): 68-74. [CrossRef]

[18] Otway S, D. S. Robinson. The use of a non- ionic detergent (triton WR 1339) to determine rates of triglyceride entry into the circulation of the rat under different physiological conditions. J Physiol. 1967; 190(2): 321-332. [CrossRef]

[19] Li J, Yang M, Xu W. Enhanced oral bioavailability of fluvastatin by using nanosuspensions containing cyclodextrin. Drug Des Devel Ther. 2018; 12: 3491-3499. [CrossRef]

[20] Sharma P, Panda A, Pradhan A, Zhang J, Thakkar R, Whang C, Repka M, Murthy S. Solid-state stability issues of drugs in transdermal patch formulations. AAPS PharmSciTech. 2017; 19(1): 27-35. [CrossRef]

[21] Geevarghese R, Shirolkar S. RP-HPLC method for estimation of rosuvastatin calcium from bulk and transdermal dosage form. Int J Pharm Sci Res. 2018; 9(11): 4875-4879. [CrossRef]

[22] Lal N, Yadav P, Rastogi V, Verma A, Verma N . Aspects of pressure sensitive adhesives in fabricating drug-in adhesive transdermal therapeutic systems. Drug Deliv Lett. 2017; 7(1): 3-15. [CrossRef]

[23] Niharika L, Pragya Y, Vaibhav V, Lalit P, Navneet V, AnuragV. Development and evaluation of transdermal therapeutic system of metoprolol succinate using acrylic polymer. Asian J Pharm. 2016; 10(3): 178-187.

[24] Mendes M, Nunes S, Sousa J, Pais A, Vitorino C. Expanding transdermal delivery with lipid nanoparticles: a new drug-in-NLC-in-adhesive design. Mol Pharm. 2017; 14(6): 2099-2115. [CrossRef]

[25] Anod H, Gupta V, Gowda D, Manohar M. Preparation and evaluation of simvastatin transdermal film. Int. J. Appl. Pharm. 2018; 10(5): 235-238. [CrossRef]

[26] Taghizadeh S, Ardakani A, Mohamadnia F. Statistical experimental design approach to evaluate the influence of various penetration enhancers on transdermal drug delivery of buprenorphine. J Adv Res. 2015; 6: 155-162. [CrossRef]

[27] Wang J, Li Z, Sun F, Tang S, Zhang S, Pengyyue L.Evaluation of dermal irritation and skin sensitization due to vitacoxib. Toxicol Rep . 2017; 4: 287-290. [CrossRef]

[28] Bautista A, Tan M, Apostol J. Lipid-lowering property of Clausena anisum-olens in hypercholesterolemic rats. Pharm Biol. 2017; 55(1): 833-836. [CrossRef]

[29] Surya S, Kurup R, Kumar A, Carla B, Sunil C. Antihyperlipidemic effect of Ficus dalhousiae miq. stem bark on Triton WR-1339 and high fat diet induced hyperlipidemic rats. Bulletin of Faculty of Pharmacy, Cairo University. 2017; 55(1): 73-77. [CrossRef]

[30] Murugaiyah V, Ahmed Saeed M, Kuong Y, Murugesu K, Parasuraman S, Asmawi M, Sadikun A. Lipid lowering effect of hydroalcoholic extracts of Gynura procumbens in chemical and high fat diet induced hyperlipidemic rats. Phcog Mag. 2018; 14(55): 184-191. [CrossRef] 